Uşak Üniversitesi Sosyal Bilimler Dergisi

$2015,8 / 3$

\title{
Sınıf Öğretmenlerinin ve Sınıf Öğretmeni Adaylarının Kaynaştırma Eğitimine İlişkin Tutumlarının İncelenmesi*
}

\author{
Bircan GÜLERYÜZ** \\ Muhammet ÖZDEMIR ${ }^{* * *}$
}

\begin{abstract}
Öz
$\mathrm{Bu}$ araştırmanın amacı, ilkokul sınıf öğretmenlerinin ve sınıf öğretmeni adaylarının kaynaştırma eğitimine karşı olan görüşlerinin belirlenmesidir. Araştırmada görüşlerin belirlenmesi için betimsel yöntem kullanılmıştır. Araştırmanın örneklemini 2012-2013 eğitim-öğretim yılında Zonguldak İli Alaplı ve Ereğli İlçelerinde görev yapmakta olan 200 sınıf öğretmeni ile Bülent Ecevit Üniversitesi Ereğli Eğitim Fakültesi Sınıf Öğretmenliği A.B.D’ında eğitim görmekte olan 195 sınıf öğretmeni adayı oluşturmaktadır. Araştırmanın nicel kısmında ise Antonak ve Larivee (1995) tarafından geliştirilen, Kırcaali-İftar tarafından Türkçeye uyarlanan "Kaynaştırmaya İlişkin Görüşler Ölçeği" kullanılmıştır. Araştırmadan elde edilen sonuçlara göre; sınıf öğretmenleri ve sınıf öğretmeni adaylarının kaynaştırma eğitimine karşı olan görüşleri arasında her hangi farka rastlanmamıştır. Sınıf öğretmenleri ve sınıf öğretmenleri adayları kaynaştırma eğitimine karşı olumlu görüşe sahip olduğu belirlenmiştir. Bunun yanında sınıf öğretmenlerinin kaynaştırma eğitimine karşı olan tutumları mesleki kıdemlerine göre değiştiği; mesleğin ilk on yılında bulunan öğretmenlerin, on yıl üstü öğretmenlere göre kaynaştırma eğitimi hakkında daha olumlu görüşe sahip oldukları belirlenmiştir. Sınıf öğretmenlerinin kaynaştırma eğitimine karşı olan görüşlerinin cinsiyete göre değişmediği belirlenmiştir.
\end{abstract}

Anahtar Kelimeler: Kaynaştırma Eğitimi, Kaynaştırma Eğitimine Karşı Tutum.

* Bu çalışma Yrd. Doç. Dr. Muhammet Özdemir danışmanlığında Bircan Güleryüz tarafından "Sınıf Öğretmenlerinin ve Sınıf Öğretmeni Adaylarının Kaynaştırma Eğitimine İlişkin Görüşlerinin Belirlenmesi (2014) başlıklı yüksek lisans tezinden üretilmiştir.

${ }^{*}$ Sinıf Öğretmeni, MEB

*** Yrd. Doç. Dr. Bülent Ecevit Üniversitesi, Ereğli Eğitim Fakültesi, İlköğretim

Bölümü, muhammetozdemir@beun.edu.tr 


\title{
To Analyze the Attitudes of Primary School Teachers and Pre-service Primary School Teachers Towards Inclusive Education
}

\begin{abstract}
The aim of this study is to determine the attitudes of primary school teachers and pre-service primary school teachers towards inclusive education. In this study, descriptive method was used for the determination of opinion. The sample of study includes 200 primary school teachers who are working in Ereğli and Alaplı, Zonguldak and 195 pre-service primary school teachers who are study at Bülent Ecevit University. And in the quantitative part of the research "Scale Of Views related with Inclusion" is used. This scale is developed by Antonak and Larivve (1995). And it is adapted in Turkish by Kurcaali-Ifftar. The quantitative analysis results showed that there are no differences between the attitudes of primary school teachers towards inclusive education. It is determined that primary school teachers and preservice primary school teachers have positive attitudes towards inclusive education. Besides, attitudes towards inclusive education depends Professional experience. Teachers who are in the very first ten years in their profession have more positive attitudes when they are compared with teachers who era working over ten years. But it is revealed that attitudes towards inclusive education don't depend on gender.
\end{abstract} Education.

Key Words: Inclusive education, Attitudes Toward Inclusive

\section{Giriş}

Devlet İstatistik Enstitüsü verilerine göre dünya nüfusunun \%14'ü, Türkiye nüfusunun ise $\% 12,29^{\prime}$ u özel gereksinimli bireylerden oluşmaktadır. Türkiye'de yaklaşık yedi milyon özel gereksinimli birey bulunmaktadır (Devlet İstatistik Enstitüsü, 2009).

Bireysel gereksinimler ve farklılıklar gözetilerek eğitim programları oluşturulması önemlidir. Bu gereksinim "özel eğitim" ihtiyacının doğmasına sebep olmaktadır. Farklılıkların belirgin olduğu bireylerde genel eğitim hizmetleri yetersiz kalmakta, özel eğitim hizmetlerine gerek duyulmaktadır (MEB, 2010).

Özel gereksinimli bireylerin topluma kazandırılmaları ve üretken bireyle haline gelmeleri eğitim imkânlarının sunulmasına bağlıdır. Özel gereksinimli bireylere sağlanan eğitim ortamları içerisinde "en az kısıtlayıcı eğitim ortamının en üst seviyesini oluşturan kaynaştırma uygulamasında, 
herhangi bir özür grubundaki öğrenciye gerekli destek hizmetler sağlanarak normal sınıf içinde eğitim görmesi söz konusudur (Gözün ve Yıkmış, 2004).

Kaynaştırma, genel eğitim içerisinde artık sıkça karşılaştığımız bir kavramdır. Çünkü özel gereksinimli bireylerin, genel eğitimin içerisinde yer alması daha yaygın hale gelmektedir. Kaynaştırma eğitiminin başarılı olması için çeşitli etkenler bulunmaktadır. Öğretmen tutumları da bu etkenler biridir. Bunun sonucu olarak da özel eğitim alanında araştırma yapan araştırmacılar kaynaştırma eğitiminin başarısının yanı sıra, genel eğitim sınıfına özel gereksinimli bireyin kaynaştırılmasında genel eğitim sınıfı öğretmenlerinin tutum ve inançlarını da incelemeye başlamışlardır (Kuzu, 2011).

Kaynaştırma eğitimi günümüzde Türkiye' de her resmi ve özel eğitim kurumlarında karşımıza çıkmaktadır. Kaynaştırma eğitiminin ilk uygulayıcları sınıf öğretmenleridir.

Sınıf öğretmenlerinin özel gereksinimli öğrenciyle özel eğitim öğretmeni ve rehber öğretmenden daha çok beraber olmaları ve eğitimöğretim faaliyetlerini birlikte yürütmeleri sebebiyle özel gereksinimli öğrencinin gelişimi açısından sınıf öğretmenlerinin önemini ve etkinliğini daha da arttırmakta olup, sınıf öğretmenlerinin kaynaştırma eğitiminin en önemli uygulayıcısı ve takipçisi konumuna getirmektedir. Alan yazından Batu (1998), Çuhadar (2006), Bilen (2007), Kargın ve diğerleri (2010), Ekşi (2010), Kuzu (2011) ve Saidoğlu (2011) tarafından yapılmış olan; öğretmenlerin kaynaştırma eğitiminde yaşadıkları sorunlara, kaynaştırma eğitimine ilişkin görüş ve tutumlarının incelenmesine yönelik çalışmalar bulunmaktadır. Fakat sınıf öğretmen adaylarının kaynaştırma eğitimine karşı olan görüşlerini belirlemeye yönelik çalışmalara pek yer almamaktadır.

Sınıf öğretmenlerinin kaynaştırma eğitimi ile ilgili bilgi, düşünce, yeterlilikleri, uygulamaları ve karşılaştığı güçlüklerine 1 şık tutması, kaynaştırma eğitimi uygulamalarına yönelik olası çözümleri ve sınıf öğretmeni adaylarının kaynaştırma eğitimine karşı olan tutumlarının

belirlenmesi bakımından literatüre önemli bir katkı sağlaması beklenmektedir.

\section{Araștırmanın Amacı ve Önemi}

$\mathrm{Bu}$ araştırmanın amacl; sınıf öğretmenlerinin ve sınıf öğretmeni adaylarının kaynaştırma eğitimine karşı olan tutumlarını belirlemektir. Kaynaştırma eğitiminin uygulayıcıları olan Sınıf Öğretmenlerinin ve Sınıf Öğretmeni adaylarının kaynaştırma eğitimine ilişkin görüşlerini belirlemek araştırmanın problemini oluşturmaktadır. Araştırmanın alt problemleri ise;

1.Sınıf öğretmenlerinin ve sınıf öğretmeni adaylarının kaynaştırma eğitimine karşı olan tutumları nasıldır? 
2.Sınıf öğretmenlerinin ve sınıf öğretmeni adaylarının kaynaştırma eğitimine karşı olan tutumları arasında farklılık var mıdır?

3.Sınıf öğretmeni adaylarının kaynaştırma eğitimine karşı olan tutumlarında cinsiyete göre anlamlı farklılık var mıdır?

4.Sınıf öğretmenlerinin kaynaştırma eğitimine karşı olan tutumlarında;

a. Mesleki kıdeme göre anlamlı fark var mıdır?

b. Cinsiyete göre anlamlı farklılık var mıdır?

\section{Araștırmanın Yöntemi}

$\mathrm{Bu}$ araştırmada sınıf öğretmeni ve sınıf öğretmeni adaylarının kaynaştırma eğitimine karşı tutumlarını farklı değişkenler açısından belirlemek amaçlandığından bu araştırmada betimsel tarama modeli kullanılmıştır. Betimleme olayların, objelerin, varlıkların, kurumların, grupların ve çeşitli alanların ne olduğunu betimlemeye/açıklamaya çalışır (Karasar, 2006).

\section{Evren ve Örneklem}

Araştırmanın evrenini 2012-2013 yılları arasında Zonguldak iline bağlı Alaplı ve Ereğli ilçelerinde görev yapmakta olan sınıf öğretmenleri ile B.E.Ü Sınıf Öğretmenliği A.B.D'ında öğrenim görmekte olan öğrenciler oluşturmaktadır. Örneklemeni ise; bu ilçelerde Milli Eğitim Bakanlığına bağlı resmi ilköğretim okullarında görev yapmakta olan 200 sınıf öğretmeni ile B.E.Ü Ereğli Eğitim Fakültesi'nde öğrenim gören 195 sınıf öğretmeni adayı oluşturmaktadır.

\section{Veri Toplama Araçları}

Araştırmada verilerin toplanması amacıyla kullanılan ölçme aracı: Sınıf öğretmenleri ve sınıf öğretmeni adaylarının kaynaştırma eğitimine olan görüşlerini belirlemek amacıyla; Antonak ve Larivee (1995) tarafından geliştirilen, Kırcaali-İftar tarafından Türkçeye uyarlanan "Kaynaştırmaya İlişkin Görüşler Ölçeği" adlı tutum ölçeğidir. Araştırmada kullanılan tutum ölçeğinin geçerlik ve güvenirlik çalışmaları Özbaba (2000) tarafından yapılmıştır. Araştırmacı tutum ölçeğini bir hafta ara ile uygulamış, elde edilen veriler arasında korelâsyonu Pearson Moment tekniği ile hesaplamış sonucunda 0.97 ile tutum ölçeğinin güvenilir olduğu göstermiştir. Testin iç tutarlık katsayılarına bakıldığında Spearman Brown 0.908, Horst 0.908 ve Cronbach 0.92 ile ifade edilmiştir. Tutarlılık ölçeğinin iç tutarlık katsayılarına bakıldığında testin güvenilir olduğu ifade edilebilir. 


\section{Verilerin Analizi ve Kullanılan İstatistiksel Teknikler}

Araştırmada "Kaynaştırmaya İlişkin Görüşler Ölçeği"nden elde edilen verilerinin analizi SPSS 17.0 istatistik programı ile yapılmıştır. Sınıf öğretmenlerinin ve öğretmen adaylarının kaynaştırma eğitimine karşı tutumları arasında istatistiksel olarak anlamlı farklılık olup olmadığını belirlemek için bağımsız gruplar için t-testi, sınıf öğretmenlerinin mesleki kıdeme göre kaynaştırma eğitimine yönelik tutumlarını belirlemek için ANOVA sonuçlarına bakılarak yapılmıştır.

\section{Bulgular}

Bu bölümde sınıf öğretmenleri ve sınıf öğretmeni adaylarına uygulanan İlköğretimde Kaynaştırmaya İlişkin Tutum Ölçeğinin analizi sonuçlarına yer verilmektedir. Araştırmanın alt problemlerine göre düzenlenen bulgular aşağıda yer almaktadır.

\section{Birinci Alt Probleme İlişkin Bulgular}

Araştırmanın "Sınıf öğretmenlerinin ve sınıf öğretmeni adaylarının kaynaştırma eğitimine karşı olan tutumları nasıldır?" şeklinde ifade edilen birinci alt problemi test etmek için, sınıf öğretmenlerine ve sınıf öğretmeni adaylarına İlköğretimde Kaynaştırmaya İlişkin Tutum Ölçeği uygulanmıştır.

Tablo 1. Kaynaştırma Eğitimine İlişkin Tutum Ölçeği Seçenekleri ile Puan Aralıkları

\begin{tabular}{lll}
\hline Seçenekler & Verilen puanlar & Puan Aralığı \\
\hline Tamamen katılıyorum & 5 & $4.20-5.00$ \\
Çok katılıyorum & 4 & $3.40-4.19$ \\
Katılıyorum & 3 & $2.60-3.39$ \\
Az katıliyorum & 2 & $1.80-2.59$ \\
Hiç katılmıyorum & 1 & $1.00-1.79$ \\
\hline
\end{tabular}

Araştırma kapsamında öğretmenlere uygulanan kaynaştırma eğitimine yönelik İlköğretimde Kaynaştırmaya İlişkin Tutum Ölçeği toplam 30 sorudan oluşmaktadır. Kullanılan 5'li likert ölçeğin skalaları, 1'den 5'e kadar puanlanan bir değerlendirme olup, ölçek seçenekleri ile yapılan puan aralıkları aşağıda verilmiştir.

Araştırmaya katılan 200 sınıf öğretmenin kaynaştırma eğitimine yönelik tutum ölçeği puan ortalamaları 3,39 yani "katıllyorum"; araştırmaya 
katılan 195 sınıf öğretmeni adayının kaynaştırma eğitimine yönelik tutum ölçeği puan ortalamaları 3,41' yani "çok katlıyorum" düzeyindedir. Elde edilen bu sonuç incelendiğinde sınıf öğretmenlerinin ve sinıf öğretmeni adaylarının kaynaştırma eğitimine karşı tutumları "çok katılıyorum" düzeyindedir.

\section{İkinci Alt Probleme İlişkin Bulgular}

Araştırmanın "Sınıf öğretmenlerinin ve Sınıf öğretmeni adaylarının kaynaştırma eğitimine karşı olan tutumları arasında farklılık var mıdır?" şeklinde ifade edilen ikinci alt problemi test etmek için, sınıf öğretmenlerine ve sınıf öğretmen adaylarına İlköğretimde Kaynaştırmaya İlişkin Tutum Ölçeği uygulanmıştır. Uygulanan ölçekten elde edilen veriler aralarında farklılık olup olmadığını ortaya koymak için $t$ testi (bağımsız gruplar için) analiz yöntemi ile değerlendirilmiştir. Değerlendirmeden elde edilen sonuçlar Tablo 2'de gösterilmiştir.

Tablo 2. Sınıf öğretmeni ve Sınıf Öğretmen Adaylarının Kaynaştırma Eğitimine Yönelik Tutumlarına İlişkin Bağımsız Gruplar İçin t Testi Sonuçları

\begin{tabular}{lccllll}
\hline & $\mathrm{N}$ & $\overline{\mathbf{X}}$ & $\mathrm{S}$ & $\mathrm{sd}$ & $\mathrm{t}$ & $\mathrm{p}$ \\
\cline { 2 - 7 } Sınıf Öğretmeni Adayı & 195 & 103,6 & 8,2 & 298 & & \\
Sınıf Öğretmeni & 200 & 101,7 & 8,7 & & 1.83 & 0.73
\end{tabular}

${ }^{*} \mathrm{p}<0.05$

İlköğretimde Kaynaştırmaya İlişkin Tutum Ölçeği puanı ortalamalarında sınıf öğretmeni adaylarının ortalamaları $\bar{X}=103,6$, sınıf öğretmenlerinin ortalamaları $\bar{X}=101,7^{\prime}$ dir. Ayrıca her iki grup için standart sapmalar sırasıyla $S=8,2$ ve $S=8,7$ olarak hesaplanmıştır. Hesaplanan $t$ değeri ve \%95 güven aralığına göre ( $p>0.05)$; sinıf öğretmeni adayları ve sınıf öğretmenlerinin kaynaştırma eğitimine yönelik tutum ölçeğinden aldıkları puanlar açısından istatistiksel olarak anlamlı bir farklılık olmadığı gözlemlenmiştir (t298=1.83 ve p>0,05).

\section{Üçüncü Alt Probleme İlişkin Bulgular}

Araştırmanın "Sınıf öğretmeni adaylarının kaynaştırma eğitimine karşı olan tutumlarında cinsiyete göre anlamlı farklılık var mıdır?" şeklinde ifade edilen üçüncü alt problemi test etmek için, sınıf öğretmeni adaylarına İlköğretimde Kaynaştırmaya İlişkin Tutum Ölçeği uygulanmıştır. Uygulanan 
ölçekten elde edilen veriler aralarında farklılık olup olmadığını ortaya koymak için $t$ testi (bağımsız gruplar için) analiz yöntemi ile değerlendirilmiştir. Tablo 3'te öğretmen adaylarının cinsiyetlerine göre kaynaştırma eğitimine yönelik tutumlarına yönelik bağımsız gruplar için ttesti sonuçları aşağıda verilmiştir;

Tablo 3. Sınıf Öğretmeni Adaylarının Cinsiyete Göre Bağımsız Gruplar İçin t Testi Sonuçları

\begin{tabular}{lllllll}
\hline Cinsiyet & $\mathbf{N}$ & $\overline{\mathbf{X}}$ & $\mathbf{S}$ & $\mathbf{S d}$ & $\mathbf{t}$ & $\mathbf{p}$ \\
\hline Kadın & 119 & 103.9 & 8.2 & 193 & 0.74 & 0.94 \\
Erkek & 76 & 103.8 & 7.9 & 193 & & \\
\hline
\end{tabular}

${ }^{*} \mathrm{p}<0.05$

Tablo 3 incelendiğinde İlköğretimde Kaynaştırmaya İlişkin Tutum Ölçeği puanı ortalamalarında kadın sınıf öğretmeni adaylarının ortalamaları $\bar{X}=103,9$, erkek sınıf öğretmeni adaylarının ise $\bar{X}=103,8^{\prime}$ dir. Kadın sınıf öğretmeni adaylarının kaynaştırma eğitimine yönelik tutum ölçeğine vermiş oldukları cevaplardan elde edilen sonuçların standart sapması 8,2 ve erkek öğretmenlerin standart sapmas1 7,9 olarak bulunmuştur (t193=0.94 ve $p>0,05)$. Hesaplanan $t$ değeri ve \%95 güven aralığına göre $(p>0.05)$; kadın sınıf öğretmeni adaylarının ve erkek sınıf öğretmeni adaylarının kaynaştırma eğitimine yönelik tutum ölçeğinden aldıkları puanlar açısından istatistiksel olarak anlamlı bir farklılık olmadığı gözlemlenmiştir (t193=0.94ve p>0,05).

\section{Dördüncü Alt Probleme İlişkin Bulgular}

Araştırmanın "Sınıf öğretmenlerinin kaynaştırma eğitimine karşı olan tutumlarının cinsiyet ve kıdeme göre değişip değişmediğini belirlemek;

a- Mesleki kıdeme göre anlamlı fark var mıdır?

b- Cinsiyete göre anlamlı farklılık var mıdır?

şeklinde ifade edilen dördüncü alt problemi test etmek için, sınıf öğretmenlerine İlköğretimde Kaynaştırmaya İlişkin Tutum Ölçeği uygulanmıştır. Uygulanan ölçekten elde edilen veriler aralarında farklılık olup olmadığını ortaya koymak için ANOVA ve t testi (bağımsız gruplar için) analiz yöntemi ile değerlendirilmiştir. 


\section{a)-Mesleki Kıdeme Göre}

Tablo 4. Sınıf Öğretmenlerinin Mesleki Kıdemlerine İlişkin Betimsel istatistik Sonuçları

\begin{tabular}{llll}
\hline Mesleki Kidem & $\mathbf{N}$ & $\overline{\mathbf{X}}$ & $\mathbf{S}$ \\
\hline A Grubu (1-10) & 101 & 103.34 & 8.85 \\
B Grubu (11-20) & 67 & 99.97 & 8.33 \\
C Grubu (21-35) & 32 & 100.25 & 8.27 \\
\hline
\end{tabular}

Tablo 4'e göre A Grubu (1-10 yıl) mesleki kıdeme sahip sınıf öğretmenlerinin Kaynaştırmaya İlişkin Tutum Ölçeği puan ortalamaları 103.34, B Grubu (11-20 y1l) mesleki kıdeme sınıf öğretmenlerinin Kaynaştırmaya İlişkin Tutum Ölçeği puan ortalamaları 99.97 ve C Grubu (2135 yıl) kıdeme sınıf öğretmenlerinin Kaynaştırmaya İlişkin Tutum Ölçeği puan ortalamaları 100.25 olarak bulunmuştur.

Tablo 5. Sınıf Öğretmenlerinin Kıdeme Göre Varyans Analizi Sonuçları

\begin{tabular}{llllll}
\hline $\begin{array}{l}\text { Varyans } \\
\text { Kaynağı }\end{array}$ & $\begin{array}{l}\text { Kareler } \\
\text { Toplami }\end{array}$ & Sd & $\begin{array}{l}\text { Kareler } \\
\text { Ortalamasi }\end{array}$ & F & P \\
\hline Gruplar içi & 541 & 2 & 270 & 3.668 & ${ }^{*} 0.027$ \\
Grupla arası & 14542 & 197 & 73 & & \\
Toplam & 15084 & 199 & & & \\
& & & & & \\
\end{tabular}

${ }^{*} \mathrm{p}<0.05$

Tablo 5'de görüldüğü gibi, sınıf öğretmenlerin hizmet yıllarına göre, Kaynaştırmaya İlişkin Tutum Ölçeği puanları arasında 0.05 anlamlılık düzeyinde anlamlı bir farklılık olduğu görülmektedir. Bu farkın hangi hizmet yılları arasında olduğunu belirlemek için yapılan Tukey testinden elde edilen bulgular Tablo 6'da verilmiştir. 
Sosyal Bilimler Dergisi 61

Tablo 6. Sınıf Öğretmenlerin Kıdem Durumlarına Göre Tukey Analizi Sonuçları

\begin{tabular}{|c|c|c|c|c|c|c|}
\hline Grup & Kidem & $\overline{\mathbf{X}}$ & $S$ & $\mathbf{F}$ & $p$ & Fark (Tukey) \\
\hline A & $1-10$ yıl & 103.3 & 8.8 & 3.29 & .027 & $\begin{array}{l}\text { A grubu (1-10 y1l) } \\
\text { /B grubu (11-20 yıl) }\end{array}$ \\
\hline B & $11-20$ yil & 99.9 & 8.3 & & & \\
\hline C & $\begin{array}{l}21 \text { yll ve } \\
\text { üstü }\end{array}$ & 100.2 & 8.2 & & & \\
\hline
\end{tabular}

Tablo 6 incelendiğinde; A grubunda (1-10 yıl) yer alan sinıf öğretmenlerinin Kaynaştırmaya İlişkin Tutum Ölçeği puan ortalamaları ile B $(11-20$ yıl) ve $C$ grubunda yer alan sinıf öğretmenlerinin puan ortalamalarından 0.05 düzeyinde farklılık gösterdiği belirlenmiştir. A grubunda (1-10 yıl) yer alan sınıf öğretmenlerinin $(x=103.3)$ ortalama ve $B$ grubunda (11-20 yıl) yer alan sinıf öğretmenlerinin ( $x=99.9)$ ve $C$ grubunda yer alan sınıf öğretmenlerinin ( $x=100.2)$ ortalama sonuçları elde edilmiştir. Elde edilen anket bulgularına göre A grubunda (1-10 yil) yer alan sinif öğretmenlerinin kaynaştırma eğitimine yönelik tutumlarının, B grubunda (11-20 yıl) yer alan sınıf öğretmenlerine göre daha olumlu yönde görüşe sahip oldukları belirlenmiştir.

\section{b) Cinsiyete göre;}

Tablo 7'de öğretmenlerin cinsiyetlerine göre Kaynaştırmaya İlişkin Tutum Ölçeğine yönelik bağımsız gruplar için t-testi sonuçları aşağıda verilmiştir;

Tablo 7. Sınıf Öğretmenlerinin Cinsiyete Göre Bağımsız Gruplar için t Testi Sonuçları

\begin{tabular}{lllllll}
\hline Cinsiyet & $\mathbf{N}$ & $\overline{\mathbf{X}}$ & $\mathbf{S}$ & $\mathbf{S d}$ & $\mathbf{t}$ & $\mathbf{p}$ \\
\hline Kadın & 103 & 102.3 & 8.2 & 198 & 0.97 & 0.33 \\
Erkek & 97 & 101.1 & 9.1 & 198 & 0.96 & \\
\hline
\end{tabular}

${ }^{*} \mathrm{p}<0.05$

Tablo 7 incelendiğinde Kaynaştırmaya İlişkin Tutum Ölçeği puanı ortalamalarında kadın sınıf öğretmenlerinin ortalamaları $\bar{X}=102,3$, erkek sınıf öğretmenlerinin ise $\bar{X}=101,1^{\prime}$ dir. Kadın sınıf öğretmenlerin kaynaştırma eğitimine yönelik tutum ölçeğine vermiş oldukları cevaplardan elde edilen sonuçların standart sapması 8,2 ve erkek öğretmenlerin standart sapması 
9,1'dir.Hesaplanan $t$ değeri ve \%95 güven aralığına göre ( $p>0.05$ ); kadın sınıf öğretmenleri ve erkek sınıf öğretmenlerinin kaynaştırma eğitimine yönelik tutum ölçeğinden aldıkları puanlar açısından istatistiksel olarak anlamlı bir farklılık olmadığı gözlemlenmiştir (t198=0.33 ve p>0,05).

\section{Tartışma, Sonuç ve Öneriler}

Araştırmanın bulgularından elde edilen sonuçlara göre:

"Kaynaştırmaya İlişkin Görüşler Ölçeği” bulgularına göre sınıf öğretmenleri ve sınıf öğretmeni adayları; kaynaştırma eğitimine karşı olumlu tutuma sahip oldukları sonucuna ulaşılmıştır. İlgili alınyazın incelendiğinde mevcut araştırmada elde edilen sonuçlara benzer sonuçlar elde edilmiştir (Avramidis ve Norwich, 2002; Varlıer, 2004). Kuzu (2011), yaptığ 1 araştırmada öğretmen adaylarının kaynaştırma eğitimine yönelik tutumlarını çeşitli değişkenler ve öz duyarlık düzeyleri açısından karşılaştırmıştır. Araştırmanın sonuçlarına göre öğretmen adaylarının kaynaştırma eğitimine ilişkin tutumlarının olumlu olduğunu belirlemiştir.

Avramidis ve Norwich (2002)'e göre, öğretmenlerin kaynaştırmaya karşı olan tutumlarına ve kaynaştırma okullarındaki çocukların özel eğitim ihtiyaçlarına yer vermiştir. Verilerin analizi sonucunda elde edilen bulgularda öğretmenlerin kaynaştırma eğitimine karsı olumlu tutuma sahip olduklarını belirtmesi bakımından mevcut araştırma bulguları ile benzerdir.

Kuzu (2011), yaptığı araştırmada öğretmen adaylarının kaynaştırma eğitimine yönelik tutumlarını çeşitli değişkenler ve öz duyarlık düzeyleri açısından karşılaştırmak amaçlanmıştır. Araştırmanın sonuçları mevcut araştırma sonuçları ile benzer yani; öğretmen adaylarının kaynaştırma eğitimine ilişkin tutumlarının genellikle olumlu olduğu şeklindedir.

Varlıer (2004), okul öncesi öğretmenin kaynaştırmaya ilişkin görüşlerini belirlemek amacıyla yaptığı araştırmada da mevcut araştırma sonuçları ile benzer sonuçlar bulmuştur. Çoğunluğun kaynaştırma eğitim verilmesine ve uygulanmasına ilişkin görüsslerinin olumlu olduğu belirlenmiştir.

Sınıf öğretmeni adayları ve sınıf öğretmenlerinin İlköğretimde Kaynaştırmaya İlişkin Tutum Ölçeğinden aldıkları puanlar açısından kaynaştırma eğitimine yönelik tutumları arasında her hangi bir fark olmadığı sonucuna ulaşılmıştır.

Sınıf öğretmeni adaylarının ve sınıf öğretmenlerinin cinsiyetlerine göre kaynaştırma eğitimine yönelik tutumları arasında anlamlı bir farklılık olmadığı belirlenmiştir. Yekeler (2005), araştırmasında sınıf öğretmenlerinin kaynaştırma eğitimine yönelik tutumlarının değerlendirmesini amaçlamıştır. Araştırma sonucunda; sınıf öğretmenlerinin cinsiyete, mezun oldukları 
bölüme ve mesleki kıdemlerine göre kaynaştırma eğitimine ilişkin tutumlarında anlamlı bir fark bulunamamıştır. Mevcut araştırma ile cinsiyet ve kıdemlerine değişkenlerine göre aynı bulguları ortaya koymaktadırlar.

Sınıf öğretmenlerin hizmet yıllarına göre, kaynaştırma eğitimi tutum ilişkin puanları arasında 0.05 anlamlılık düzeyinde anlamlı bir farklılık olduğu görülmektedir. Bu farkın mesleki kıdeme göre; A grubunda (1-10 yıl) yer alan sınıf öğretmenlerinin kaynaştırma eğitimine yönelik tutumlarının, $B$ grubunda (11-20 yıl) yer alan sinıf öğretmenlerine göre daha olumlu yönde görüşe sahip oldukları sonucu ortaya çıkmıştır.

Griffin (2008), araştırmasında kaynaştırma sınıflarında görev alan ilkokul öğretmenlerinin kaynaştırma eğitimine yönelik tutumlarını belirlemeyi amaçlamıştır. Araştırma sonuçları göreve yeni başlayan öğretmenlerin kaynaştırmaya karşı olan tutumlarının tecrübeli öğretmenlere kıyasla daha olumlu olduğunu ve kadınların erkeklere göre daha olumlu tutum sergilediklerini göstermiştir. Mevcut araştırmada da göreve yeni başlayan öğretmenlerin kaynaştırmaya karşı olan tutumlarının tecrübeli öğretmenlere kıyasla daha olumlu olduğu bulgusunu ortaya koymaktadır.

Araştırmadan elde edilen sonuçlara göre ileride yapılacak çalışmalarda sınıfında kaynaştırma eğitimi vermiş ve vermekte olan öğretmenlerin mesleki tükenmişlik düzeyleri araştırılabilir.

\section{Kaynakça}

ANTONAK, R. F., ve LARRIVEE, B. (1995). Psychometric Analysis and Revision Of The Opinions Relative To Mainstreaming Scale, Exceptional Children, 6 (2).

AVRAMIDIS, E. ve BRAHM N. (2002). Teachers' Attitudes Towards İntegration / İnclusion: A Review Of The Literature, Eur. J. of Special Needs Education, Vol. 17 (2), 129-147.

BATU, S. (1998). Özel Gereksinimli Öğrencilerin Kaynaştıılldığı Bir Kız Meslek Lisesindeki Öğretmenlerin Kaynaştırmaya İlişkin Görüş ve Önerileri. Doktora Tezi, Anadolu Üniversitesi Sosyal Bilimler Enstitüsü, Eskişehir.

BİLEN, E. (2007). Sinıf Öğretmenlerinin Kaynaştırma Uygulamalarında Karşılaştıkları Sorunlara İlişkin Görüşleri ve Çözüm Önerileri, Yüksek Lisans Tezi, Dokuz Eylül Üniversitesi Eğitim Bilimleri Enstitüsü, İzmir.

ÇUHADAR, Y. (2006). Illköğretim Okulu 1-5. Sinıflarda Kaynaştırma Eğitimine Tabi Olan Çocuklar İçin Bireyselleştirilmiş Ĕ̆itim Programı Hazırlanması, Uygulanması, İzlenmesi ve Değerlendirilmesi İle İlgili Olarak Sınıf Öğretmenlerinin ve Yöneticilerin Görüşlerinin Belirlenmesi, Yüksek 
Lisans Tezi, Zonguldak Karaelmas Üniversitesi Sosyal Bilimler Enstitüsü, Zonguldak.

DİE (2009). Türkiye Özürlüler Araştırması 2002, Devlet İstatistik Enstitüsü Matbaası, Baskı 2, Ankara.

GÖZÜN, Ö. ve NERMİN Y. (2004). İlköğretim Müfettişlerinin Kaynaştırma Uygulamasına İlişkin Görüş ve Önerileri, Özel Ĕ̆itim Dergisi, 5(2), 7988.

GRIFFIN, N. E. (2008). Elementary Teachers' Perceptions and Attitudes Toward The Inclusion of Englihs Language Learners In Mainstream Classrooms, Doktora tezi, Tennessee State University College of Education, Tennessee.

KARASAR, N.(2006). Bilimsel Araştırma Yöntemi. Ankara: Nobel Yayın Dağıtım

KARGIN, T.; GÜLDENOĞLU, B. ve ŞAHINN, F., (2010). Genel Eğitim Sınıflarındaki Özel Gereksinimli Öğrenciler için Yapılması Gereken Uyarlamalara İlişkin Sınıf Öğretmenlerinin Görüşlerinin İncelenmesi", Kuram ve Uygulamada Eğitim Bilimleri, 10(4), 2431-2464

KUZU, S. (2011). Öğretmen Adaylarının Kaynaştırma Eğitimine Yönelik Tutumları ve Öz Duyarlılık Düzeylerinin Karşılaştırılması, Yüksek Lisans Tezi, Marmara Üniversitesi Ĕ̆itim Bilimleri Enstitüsü, İstanbul.

MEB (2010). Okullarımızda Neden Niçin Nasıl Kaynaştırma-Yönetici, Öğretmen Ve Aile Kılavuzu, Aygül Ofset, Ankara.

ÖZBABA, N. (2000). Okul Öncesi Eğitimcilerin Ve Ailelerin Özel Eğitime Muhtaç Çocuklar İle Normal Çocukların Entegrasyonuna Karşı Tutumları, Yüksek Lisans Tezi, Marmara Üniversitesi Eğitim Bilimleri Enstitüsü, İstanbul.

SAİDOĞLU, Ö. (2011). Sınıf Öğretmenlerinin Kaynaştırmaya İlişkin Sorunları, Beklentileri ve Önerilerine Yönelik Nitel Bir Araştırma, Doktora tezi, Uludă̆ Üniversitesi Ĕ̆itim Bilimleri Enstitüsü, Bursa.

VARLIER, G. (2004). Okul öncesi eğitim öğretmenlerinin kaynaştırmaya ilişkin görüşleri. Yüksek Lisans Tezi, Anadolu Üniversitesi, Sosyal Bilimler Enstitüsü, Eskişehir

YEKELER, B. (2005). Sınıf Öğretmenlerinin Kaynaştırma Eğitimine Yönelik Tutumlarının Bazı Psiko Sosyal Değişkenler Açsından İncelenmesi, Yüksek Lisans Tezi, Cumhuriyet Üniversitesi Sosyal Bilimler Enstitüsü, Sivas. 